\title{
Protective effect of decorin on acute ischaemia-reperfusion injury in the rat kidney
}

Cabir Alan'1, Hasan Kocoglu², Ramazan Altıntas ${ }^{3}$, Bülent Alıcl, Ahmet Resit Ersay ${ }^{1}$

1Department of Urology, Faculty of Medicine, Canakkale Onsekiz Mart University, Turkey 2Department of Urology, Canakkale Military Hospital, Turkey

${ }^{3}$ Department of Urology, Cerrahpasa Faculty of Medicine, Istanbul University, Turkey

Submitted: 3 October 2010

Accepted: 22 February 2011

Arch Med Sci 2011; 7, 2: 211-216

DOI: 10.5114/aoms.2011.22069

Copyright @ 2011 Termedia \& Banach

\begin{abstract}
Introduction: Transforming growth factor- $\beta 1$ (TGF- $\beta 1$ ) has a crucial role in collagen synthesis and fibrosis. TGF- $\beta 1$ can be antagonized and/or reduced by the action of certain agents. We propose to identify the role of decorin in treatment of tubular and interstitial fibrosis and in the inhibition of TGF- $\beta 1$ in an acute ischaemic kidney.

Material and methods: We grouped 34 female Sprague Dawley type rats into 3 groups as 9 sham, 9 ischaemia-reperfusion (I/R) and $16 \mathrm{I} / \mathrm{R}+$ decorin respectively. The rats in the $I / R+$ decorin group had decorin administered intraperitoneally at the dose of $0.1 \mathrm{mg} / \mathrm{kg}$ for 9 days after reperfusion. After 9 days, all the rats in the 3 groups were unilaterally nephrectomized. The TGF- $\beta 1$ level was measured immunohistochemically in the nephrectomized material. Results: The TGF- $\beta 1$ level was lower in the I/R + decorin group. Evaluation of apoptotic activity level by caspase staining showed a statistically significant difference between the 3 groups. The number of caspase stained cells was lower in the I/R + decorin group. The amount of collagen in interstitial tissue was higher in the I/R group than in the I/R + decorin group, but this difference was not statistically significant.

Conclusions: We found that the TGF- $\beta 1$ level - the so-called initiator of fibrotic activity - and apoptotic activity were low in the I/R + decorin group. Additional studies must be performed to understand the role of decorin in inhibition of TGF- $\beta 1$ and to assess decorin's routine use in acute renal ischaemia.
\end{abstract}

Key words: transforming growth factor- $\beta 1$, decorin, glomerulosclerosis.

\section{Introduction}

Renal ischaemia is observed in conditions such as renal transplantation, partial nephrectomy, cardiopulmonary bypass, sepsis, various urological interventions and hydronephrosis. Ischaemia reperfusion damage may give rise to stimulation of tumour necrosis factors (TNF), cytokines such as interferon and TGF- $\beta 1$ (transforming growth factor- $\beta 1$ ) in kidney tissue [1].

TGF- $\beta 1$ stimulates synthesis of an extracellular matrix in the mesangium and between epithelial cells. TGF- $\beta 1$ is a cytokine that plays a key role in pathogenesis of fibrosis. According to the authors TGF- $\beta 1$ is the most important growth factor in pathogenesis of glomerulosclerosis [2, 3]. TGF- $\beta 1$ is excessively found in thrombocytes. When tissue damage occurs, it is excreted by degranulation and provides chemoattraction of inflammatory cells and thrombocytes which are responsible for fibrosis.

\section{Corresponding author:}

Assis. Prof. Cabir Alan MD, PhD

Barbaros mh Umit

Serdaroglu cd

Hasret Sit. A1 blok d: 13

Canakkale, Merkez, Turkey

Phone: +902862635950

E-mail: cabir1@yahoo.com 
It is postulated that TGF- $\beta 1$ activation is initiated by mechanical changes due to trauma and/or an inflammatory process [4-6]. Moreover, hypoxic media caused by vascular insufficiency may enhance TGF- $\beta 1$ synthesis. Some studies have found that the crucial role of TGF- $\beta 1$ in collagen synthesis and fibrosis may be antagonized and/or reduced by the action of certain agents. Among these agents decorin has an important role because it is naturally found in the body and has a higher specificity [7, 8]. Decorin, like other biglycans, fibromodulin and lumican, is found excessively around the tubulus. Decorin neutralizes TGF- $\beta 1$ activity, and is used in treatment of TGF- $\beta 1$ growth factor-producing tumours and diseases presenting with fibrotic reactions [9-13]. According to the literature mentioned above it was hypothesized that decorin may be helpful in the treatment of renal ischaemia-related events.

In our study we aim to identify the role of the proteoglycan decorin in the treatment of tubular and interstitial fibrosis and the association between TGF- $\beta 1$ and renal fibrosis and apoptosis in an acute ischaemic kidney.

\section{Material and methods}

We grouped 34 female Sprague Dawley rats, mean weight $200 \mathrm{~g}$ (186-220 g), into 3 groups as 9 sham, 9 ischaemia-reperfusion (I/R) and 16 I/R + decorin. All subjects were kept in boxes at a temperature of $22 \pm 2^{\circ} \mathrm{C}$. Four rats inhabited each box.

All the rats were taken to the experiment table and sedated with ketamine $100 \mathrm{mg} / \mathrm{kg}$ (Ketalar, Eczacıbașı, Turkey). During the experiment body temperature was kept at $36-38^{\circ} \mathrm{C}$ by a heated table controlled by a rectal thermometer. The anterior abdominal wall was incised on the median line. The left renal pedicle was found and blood circulation stopped via an atraumatic vascular clamp. After 60 min of ischaemia the clamps were released and blood circulation was allowed. After recirculation a colour change was observed in the kidney for 2 min. The incision was closed and cleaned with 10\% povidone. In order to replenish fluid loss during the operation subcutaneous saline was applied at a rate of $5 \%$ of body mass. The rats in the $1 / R+$ decorin group were administered decorin (Sigma-Aldrich) intraperitoneally at a dose of $0.1 \mathrm{mg} / \mathrm{kg}$ for 9 days after reperfusion. In the sham group, their renal pedicles were identified after dissection and the procedure was ended without clamping.

After 9 days, all the rats in the 3 groups were unilaterally nephrectomized under $100 \mathrm{mg} / \mathrm{kg}$ ketamine anaesthesia. Nephrectomized kidneys were divided into 2 pieces from the pelvis and kept in $10 \%$ formaldehyde for pathological tests and kept at $-70^{\circ} \mathrm{C}$ for biochemical tests. Tissue samples were examined with Masson's Trichrome staining to evaluate collagen tissue; ImmunoCruz staining to evaluate TGF- $\beta 1$ values; and caspase 3 staining to evaluate apoptotic activity.

Lipid peroxidation (LPX) and superoxide dismutase (SOD) enzyme levels were tested biochemically. To detect SOD and LPX enzyme activities in kidney tissue, $50 \mathrm{mM}$ phosphate buffer ( $\mathrm{pH}$ 7.4) was prepared. SOD activity was measured according to the method described by Fridovich [14]. This method employs xanthine and xanthine oxidase to generate superoxide radicals that react with $p$-iodonitrotetrazolium violet to form a red formazan dye that was measured at $505 \mathrm{~nm}$. A SOD activity was expressed as U/g wet tissue. The procedure described by Ohkawa et al. [15] was followed to estimate the LPX. The principle depends on the reaction between thiobarbituric acid with malondialdehyde, a secondary product of LPX, at $\mathrm{pH}$ 4. The reddish pink colour developed was measured at $532 \mathrm{~nm}$, which indicates the extent of peroxidation. The extent of LPX is expressed as $\mathrm{nmol} / \mathrm{g}$ wet tissue.

Tissue samples for histopathological tests were fixed in $10 \%$ formalin. They were embedded in paraffin blocks and sliced to $4 \mu \mathrm{m}$. Biopsy preparations were stained with haematoxylin-eosin (H/E) and Masson's trichrome stain (to evaluate collagen tissue) before examination by a specialist pathologist under light microscopy. Each preparation of nephrectomy materials was examined in 20 different magnification areas for cell counts. Kidney tissue sections were stained immunohistochemically with polyclonal antibody of TGF s1 (ImmunoCruz TM Staining System, sc-146K:TGF-s1(V) K-Santa Cruz Biotechnology) on Poly-L-Lysine coated slides. To determine caspase 3 activity extracted kidneys were centrifuged and supernatants collected. Protein extracts $(50 \mu \mathrm{g})$ were diluted in $1 \mathrm{ml}$ of protease assay buffer. Samples were analysed using a fluorimeter.

For the evaluation of all results, ANOVA, Tukey's $b$ and Kruskal-Wallis tests were used. Values of $p<0.001$ were considered significant. Results are presented as mean \pm SD.

\section{Results}

ImmunoCruz staining determined that the number of TGF- $\beta 1$ containing cells was significantly different in the three groups. The numbers of cells stained with TGF- $\beta 1$ in a 20 magnification area in sham, I/R and I/R + decorin groups were $47 \pm 25.39$ (range: 8-90), $286 \pm 111.18$ (range: 175-530) and $46.89 \pm 13.57$ (range: $27-68$ ) respectively (Table I, Figures 1-2). TGF- $\beta 1$ stained cells were lower in the $\mathrm{I} / \mathrm{R}+$ decorin group $(p<0.001)$.

To evaluate apoptotic activity levels, caspase staining indicated a statistically significant diffe- 
Table I. Results of three groups

\begin{tabular}{|lccc|}
\hline & Sham $(n=9)$ & I/R $(n=9)$ & I/R + decorin $(n=16)$ \\
\hline SOD [U/g wet tissue] & $32.31 \pm 4.08$ & $47.52 \pm 3.76$ & $57.45 \pm 3.48$ \\
\hline LPX [nmol/g wet tissue] & $30.78 \pm 2.34$ & $35.56 \pm 4.56$ & $32.14 \pm 4.32$ \\
\hline Caspase & $1251.56 \pm 232.40$ & $2416.63 \pm 360.78$ & $169.11 \pm 73.15$ \\
\hline TGF- $\beta 1$ & $47.00 \pm 25.39$ & $286.19 \pm 111.18$ & $46.89 \pm 13.57$ \\
\hline
\end{tabular}

I/R - ischaemia-reperfusion, SOD - superoxide dismutase, LPX - lipid peroxidation, TGF - transforming growth factor

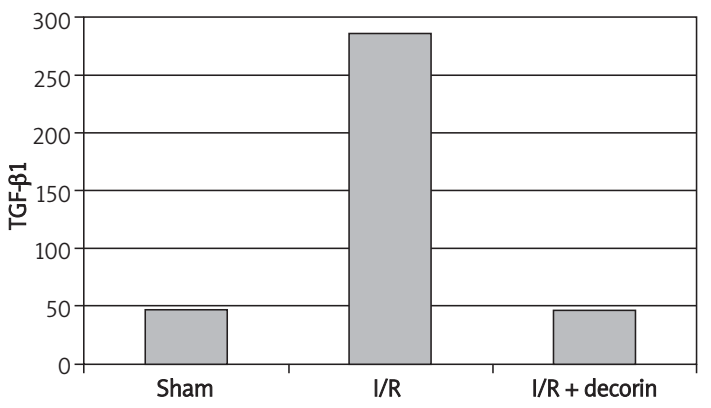

Figure 1. TGF- 1 stained cell numbers

rence between the 3 groups in the case where all the stained cells are counted. The number of caspase stained cells was lower in the I/R + decorin group. The results for sham, I/R and I/R + decorin groups were $1251.56 \pm 232.40$ (range: $811-1359$ ), $2416.63 \pm 360.78$ (range: $1969-3023$ ) and 169.11 \pm 73.15 (range: 66-253) (Table I, Figures 3-4).

Examination of Masson's trichrome staining of nephrectomy materials (to evaluate collagen tissue) showed that the amount of collagen in interstitial tissue was higher in the I/R group than in the I/R + decorin group. This difference was not statistically significant.

The levels of the enzyme lipid peroxidase, which exists in the I/R mechanism, and the SOD enzyme, which is produced to prevent this damage, were biochemically assessed. Comparing superoxide dismutase levels in sham, I/R and I/R + decorin groups proved the last group to have the highest value: $32.31 \pm 4.08$ (range: $25-36.5$ ), $47.52 \pm 3.76$ (range: $42.79-53.07$ ) and $57.45 \pm 3.48$ (range: 52.76 -

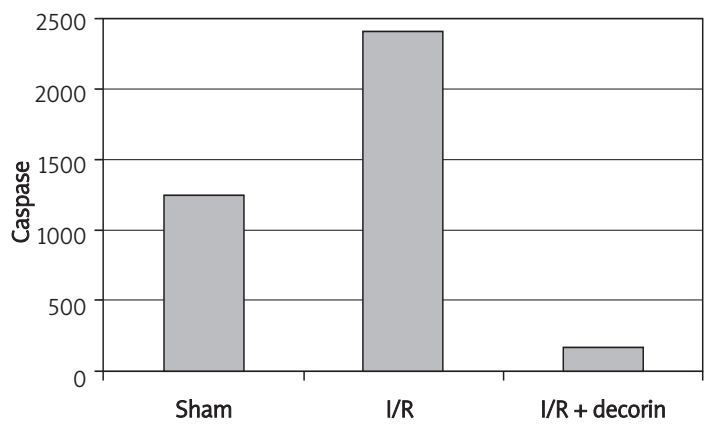

Figure 3. Caspase stained cell numbers

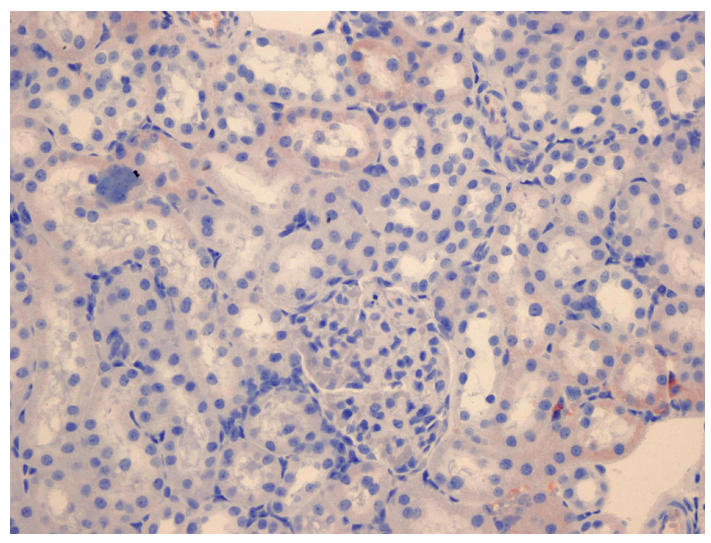

Figure 2. In the decorin administered group, fewer cortical renal tubular cells show cytoplasmic TGF $\beta-1$ positivity compared to the control group $($ TGF $\beta-1 \times 400)$

63.19) (unit/g wet tissue) respectively. There was a statistically significant difference between the three groups $(p<0.001)$ (Table I).

A statistically significant difference was observed in evaluating the three groups for lipid peroxidation. The enzyme levels for sham, I/R and I/R + decorin groups were $30.78 \pm 4.56$ (range: $24.96-37.12$ ), 35.56 \pm 2.34 (range: $32-38.4$ ) and $32.14 \pm 4.32$ (range: $26.84-$ $38.4)(\mathrm{nmol} / \mathrm{g}$ wet tissue) respectively $(p<0.001)$ (Table I).

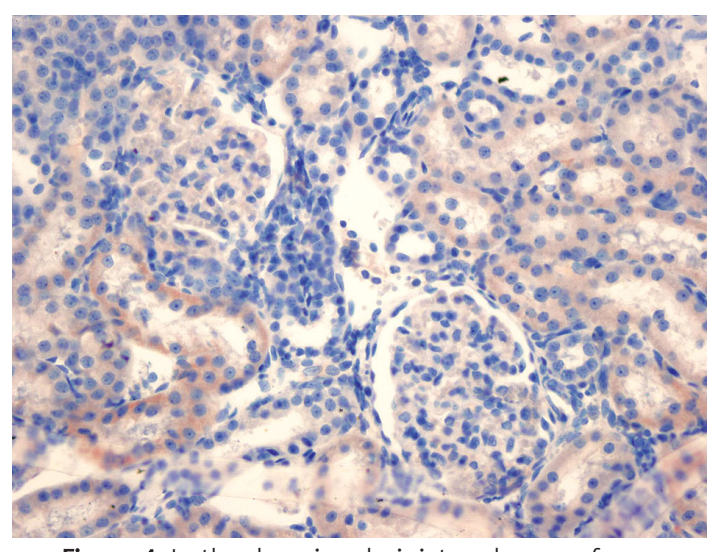

Figure 4. In the decorin administered group, fewer cortical renal tubular cells show cytoplasmic caspase positivity compared to the control group (Caspas $\times 400$ ) 


\section{Discussion}

Decorin is a member of the small leucine-rich proteoglycans (SLRPS) family. SLRPs interact with various cytokines, including TGF- $\beta$, bone morphogenic protein, Wnt-l-induced secreted protein-I, von Willebrand factor, platelet-derived growth factor and tumour necrosis factor- $\alpha[16,17]$. Decorin, biglycan, asporin, and fibromodulin bind the profibrotic cytokine TGF- $\beta[18,19]$. Besides inhibition of TGF- $\beta$-mediated fibrosis, the binding of decorin to TGF- $\beta$ has significant biological implications in regulating a number of cellular processes, e.g. modulation of cell proliferation [20], inhibition of repressive effects of TGF- $\beta$ on macrophages leading to their activation [21], and suppression of TGF- $\beta$-dependent apoptosis in bone marrow stromal cells [22].

Renal ischaemia and successive reperfusion processes, the main reason for renal dysfunction, are commonly seen in renal transplantation, surgical revascularization of the renal artery, partial nephrectomy and treatment of suprarenal aortic aneurysm [23]. Renal ischaemia-reperfusion is a complex process which includes many different mechanisms such as renal vasoconstriction and diffuse tubular and glomerular damage [24]. The mechanism for defining ischaemia reperfusion damage includes anoxia, the release of reactive oxygen species (ROS) such as superoxide radicals $\left(\mathrm{O}_{2}^{-}\right)$, hydrogen peroxide $\left(\mathrm{H}_{2} \mathrm{O}_{2}\right)$, hydroxyl radicals $\left(\mathrm{OH}^{-}\right)$through reperfusion, neutrophil accumulation and the release of additional ROS and lytic enzymes $[25,26]$. In many studies it has been shown that ROS has a crucial role in ischaemia-reperfusion via lipid peroxidation of cells [25-27]. By fatty acid peroxidation the membrane structure and function of mitochondrial lysosomes may change [25]. In our study lipid peroxidation levels in the sham group were statistically significant in comparison with the $I / R$ and $I / R+$ decorin group. In the I/R + decorin group this level was statistically higher than the sham group but lower than the I/R group.

A SOD is an antioxidant agent found in renal cells. It is a natural protector against injury caused by free radicals that are the end products of ischaemia and reperfusion $[25,27]$. In our study SOD levels were compared in the three groups and found to be statistically different. In the I/R group its level was statistically higher than the sham group. In the I/R + decorin group this level was significantly higher. These data imply that the amount of this protective agent produced in the organ increased to prevent damage. In terms of the mechanism describing the ischaemia and reperfusion damage, this damage is reduced by decorin secretion and the amount of protective agent rises. There is no publication that determines the relationship between lipid peroxidation, SOD and decorin levels. Some articles relate increments in the TGF- $\beta 1$ level by superoxide via induction of gene expression in cardiac fibroblasts [28]. In another study the preventive effect of decorin on adhesion and fibrosis via TGF- $\beta 1$-dependent and independent mechanisms, and the role of cytokines on ischaemia reperfusion were investigated [29]. The effect of decorin on ischaemia-reperfusion is conducted through unidentified mechanism pathways. In previous studies, excessive production of TGF- $\beta 1$ was detected as the main reason for tissue fibrosis after illness and tissue damage [30]. It was shown that TGF- $\beta 1$ is an important cytokine in scar formation and that its production increases the tissue repair process. Additionally decorin has some roles in biological functions such as matrix formation [31, 32], altering the cell adhesion strength and structure by use of fibronectin and thrombospondin $[32,33]$ and controlling the activity of TGF- $\beta 1$ in tissue fibrosis [33-36]. Decorin can also be used in renal parenchymal diseases as well as pulmonary and vascular disorders to reduce tissue fibrosis [10-13]. A previous study showed that renal ischaemia and reperfusion significantly induced tubular necrosis and inflammatory cell infiltration on the first day, and tubular atrophy and interstitial fibrosis by the eighth day [37]. Being exceptionally different from the other literature this study is based on this fact. This study evaluated the TGF- $\beta 1$ level, the effect of externally administered decorin on the TGF- $\beta 1$ level, and the influence of this effect on fibrosis and apoptotic changes. In another study indium stained decorin was administered to rats with a dose of 0.02-0.1 mg/ $\mathrm{kg}$ and its metabolism in the vascular system was observed. Seventy percent of administered decorin accumulated in the liver in the first $10 \mathrm{~min}$. The residual amount was detected in the kidney, spleen and urine. There was no significant radioactive accumulation in heart, lungs and muscle. Additionally it was found that as the dose increases, its metabolism rate slows [38]. In our study, decorin was given at a dose of $0.1 \mathrm{mg} / \mathrm{kg}$ - higher than the physiological limits. Contrary to former articles, we did not observe significant fibrotic changes after the assessment of standard staining methods displaying collagen tissue production and fibrosis. However, the assessment of the results of immunohistochemical staining methods displayed apoptotic changes (caspase 3 ) and TGF- $\beta 1$ levels (TGF- $\beta 1$ ImmunoCruz Staining System) showed a statistically significant difference between the 3 groups.

Immunohistochemical staining for apoptotic changes showed that the number of caspasestained cells was lower in the I/R + decorin group. The TGF- $\beta 1$ level was also lower in the I/R + decorin group than in the I/R group. In light of this fact, apoptotic activity and the TGF- $\beta 1$ level, known to 
be the initiator of fibrotic activity, were lower in the I/R + decorin group. In a similar study, apoptosis in tubular epithelial cells and the rise in TGF- $\beta 1 \mathrm{~m}$-RNA levels were doubled in rats which were subjected to decorin abstinence and post-ureteral obstruction [39]. However, in that study decorin was not administered as a treatment option.

In conclusion, TGF- $\beta 1$ can cause renal dysfunction by means of interstitial and glomerular fibrosis as a response to acute ischaemia. We found that the TGF- $\beta 1$ level - the so-called initiator of fibrotic activity - and apoptotic activity were low in the I/R + decorin group. Additional studies must be performed to understand the role of decorin in inhibition of TGF- $\beta 1$ and for assessment of decorin's routine use in acute renal ischaemia.

\section{References}

1. Kalman S. Cytokins and growth factors in renal injury. J Turk Soc Nephrol 2002; 11: 140-3.

2. Mozes MM, Böttinger EP, Jacot TA. Renal expression of fibrotic matrix proteins and of transforming growth factorbeta1 (TGF-beta1) isoforms in TGF-beta1 transgenic mice. J Am Soc Nephrol 1999; 10: 271-80.

3. Border WA, Okuda S, Languino LR. Suppression of experimental glomerulonephritis by antiserum against transforming growth factor beta1. Nature 1990; 346: 371-4.

4. Border W, Noble N. Transforming growth factor beta in tissue fibrosis. N Engl J Med 1994; 11: 1286-92.

5. Xing Z, Tremblay G, Gauldie PJ. Overexpression of GM-CSF induces pulmonary granulation tissue formation and fibrosis by induction of TGFbeta1 and myofibroblast accumulation. Am J Pathol 1997; 150: 59-66.

6. Xing Z, Jordana M, Gauldie J. Cytokines and pulmonary inflammatory and immune diseases. Histol Histopathol 1999; 14: 185-201.

7. Yamaguchi Y, Mann DM, Ruoslahti E. Negative regulation of transforming growth factor-betal by the proteoglycan decorin. Nature 1990; 346: 281-4.

8. Isaka Y, Brees DK, Ikegaya K. Gene therapy by skeletal muscle expression of decorin prevents fibrotic disease in rat kidney. Nat Med 1996; 12: 418-23.

9. Patel S, Santra M, McQuillan DJ. Decorin activates the epidermal growth factor receptor and elevates cytosolic Ca2+ in A431 carcinoma cells. J Biol Chem 1998; 273: 3121-4.

10. Fischer JW, Kinsella MG, Clowes MM. Local expression of bovine decorin by cell-mediated gene transfer reduces neointimal formation after baloon injury in rats. Circ Res 2000; 86: 676-83.

11. Giri SN, Hyde DM, Braun RK. Antifibrotic effect of decorin in a bleomycin hamster model of lung fibrosis. Biochem Pharmacol 1997; 54: 1205-16.

12. Isaka Y, Brees DK, Ikegaya K. Gene therapy by skeletal muscle expression of decorin prevents fibrotic disease in rat kidney. Nat Med 1996; 2: 418-23.

13. Kolb M, Margetts PJ, Galt T. Transient transgene expression of decorin in the lung reduces the fibrotic responce to bleomycin. Am J Respir Crit Care Med 2001; 163: 770-7.

14. Fridovich I. Superoxide radical: an endogenous toxicant. Ann Rev Pharmacol Toxicol 1983; 23: 239-57.
15. Ohkawa H, Ohishi N, Yagi K. Assay for lipid peroxides in animal tissues by thiobarbutiric acid reaction. Anal Biochem 1979; 95: 351-8.

16. Bi Y, Ehirchiou D, Kilts TM, et al. Identification of tendon stem/progenitor cells and the role of the extracellular matrix in their niche. Nat Med 2007; 13: 1219-27.

17. Inkson CA, Ono M, Bi Y, Kuznetsov SA, Fisher LW, Young MF. The potential functional interaction of biglycan and WISP-1 in controlling differentiation and proliferation of osteogenic cells. Cells Tissues Organs 2009; 189: 153-7.

18. Hildebrand A, Romaris M, Rasmussen LM, et al. Interaction of the small interstitial proteoglycans biglycan, decorin and fibromodulin with transforming growth factor beta. Biochem J 1994; 302: 527-34.

19. Nakajima M, Kizawa H, Saitoh M, Kou I, Miyazono K, Ikegawa S. Mechanisms for asporin function and regulation in articular cartilage. J Biol Chem 2007; 282: 32185-92.

20. Li X, McFarland DC, Velleman SG. Extracellular matrix proteoglycan decorin-mediated myogenic satellite cell responsiveness to transforming growth factor-beta1 during cell proliferation and differentiation Decorin and transforming growth factor-beta1 in satellite cells. Domest Anim Endocrinol 2008; 35: 263-73.

21. Comalada M, Cardo M, Xaus J, et al. Decorin reverses the repressive effect of autocrine-produced TGF-beta on mouse macrophage activation. J Immunol 2003; 170: 4450-6.

22. Bi $\mathrm{Y}$, Stuelten $\mathrm{CH}$, Kilts $\mathrm{T}$, et al. Extracellular matrix proteoglycans control the fate of bone marrow stromal cells. J Biol Chem 2005; 280: 30481-9.

23. Defraigne JQ, Detry O, Pincemail J. Direct evidence of free radical production after ischemia and reperfusion and protective effect of desferrioxamine: ESR and vitamin E studies. Eur J Vasc Surg 1994; 8: 537-43.

24. Bird JE, Milhoan K, Wilson CB. Ischemic acute renal failure and antioxidant therapy in the rat: the relaxation between glomerular and tubular dysfunction. J Clin Invest 1988; 81: 1630-8.

25. Paller MS, Hoidal JR, Ferris TF. Oxygen free radical in ischemic acute renal failure in the rat. J Clin Invest 1984; 74: 1156-64.

26. Bonventre JV. Mechanism of ischemic acute renal failure. Kidney Int 1993; 43: 1160-78.

27. Rhoden EL, Rhoden CR, Mauri M. Experimental model of renal ischemia-reperfusion in rats: study of the stress oxidative induced by oxygen-derived free radicals. J Urol 1999; 25: 431-5.

28. Li PF, Dietz R, Harsdorf RV. Superoxide induces apoptosis in cardiomyocytes, but proliferation and expression of transforming growth factor-beta1 1 in cardiac fibroblasts. FEBS Letters 1999; 448: 206-10.

29. Fukui N, Fukuda A, Kojima K. Suppression of fibrous adhesion by proteoglycan decorin. J Orthop Res 2001; 19: 456-62.

30. Border W, Noble N. Transforming growth factor beta in tissue fibrosis. N Engl J Med 1994; 331: 1286-92.

31. Vogel KG, Paulsson M, Heinegard D. Specific inhibition of type I and II collagen fibrillogenesis by the small proteoglycan of tendon. Biochem J 1984; 223: 587-97.

32. Winnemoller M, Schmidt G, Kresse H. Influence of decorin on fibroblast adhesion to fibronectin. Eur J Cell Biol 1991; 54: 10-7.

33. Winnemoller M, Schon P, Vischer P. Interactions between thrombospondin and the small proteoglycan decorin: Interference with cell attachment. Eur J Cell Biol 1992; 59: 47-55. 
34. Yamaguchi Y, Mann DM, Ruoslahti E. Negative regulation of transforming growth factor-beta1 by the proteoglycan decorin. Nature 1990; 346: 281-4.

35. Isaka Y, Brees DK, Ikegaya K. Gene therapy by skeletal muscle expression of decorin prevents fibrotic disease in rat kidney. Nat Med 1996; 2: 418-23.

36. Patel S, Santra M, McQuillan DJ. Decorin activates the epidermal growth factor receptor and elevates cytosolic Ca2+ in A431 carcinoma cells. J Biol Chem 1998; 273 : 3121-4.

37. Hideo M, Yoshinobu T, Mitsuru H. Pharmacokinetics and disposition characteristics of recombinant decorin after intravenous injection into mice. Biochim Biophys Acta 1999; 1426: 420-8.

38. Rhoden EL, Rhoden CR, Lucas ML. The role of nitric oxide pathway in the renal ischemia-reperfusion injury in rats. Trans Immunol 2002; 10: 277-84.

39. Schaefer L, Macakova K, Raslik I. Absence of decorin adversely influences tubulointerstitial fibrosis of the obstructed kidney by enhanced apoptosis and increased inflammatory reaction. Am J Pathol 2002; 160: 1181-91. 